\title{
Evolving Nurse Leadership Role in 2020
}

\author{
Nasreen Rafiq and Farida Bibi Mughal \\ The Aga Khan University School of Nursing and Midwifery, Karachi, Pakistan
}

The dedication of the year 2020 as the international year of nurses could not be timelier. We are almost through the year, and the world has identified the pivotal role of nurses, particularly in healthcare. ${ }^{1}$ The expansion in healthcare has unlatched various opportunities for nurses that has brought the unanticipated global focus on them. ${ }^{2}$ Today, these nurses are working as the important frontline healthcare providers (HCPs), who are tirelessly working against COVID-19. ${ }^{1}$ This serves as a global reminder that consideration of nursing leadership is crucial to combat COVID-19 and facilitate smooth functioning of healthcare. Indeed, the traditional role of nurses is progressively advancing from conventional role of HCPs, who care for patients in hospitals, to active researchers, academicians, and specialists. ${ }^{2-4}$ This paper highlights the wide-ranging opportunities, the year has brought for the nursing leadership.

Today, the nurse leaders are active collaborators in researches; and they promote various evidence-based models to deliver the quality of care to patients. ${ }^{4}$ The role of nurses in the stem cell researches is the core example of this dynamic advancement. ${ }^{5}$ The onset of COVID-19 pandemic has led a new horizon to the stem cell researches, ${ }^{6}$ and nurses have been found an active part of these studies. ${ }^{7}$ From preparing the patient for stem cell transplant $^{8}$ at clinics to participate in the process, providing post-transplant care, and preparing for rehabilitation, nurses are contributing for raising the quality of patient care. ${ }^{4,5}$ It also accelerated the concept of developing and promoting specific nursing competencies for stem cell therapies. ${ }^{5}$ It has re-opened the horizon for nurses to think and prepare themselves for this role and opt towards these competencies. This can also lead to development of nurse specialist role, particularly in the research field.

Similarly, the sudden surge in COVID-19 cases has also shifted the focus of healthcare to the home health nursing services; ${ }^{9}$ hence, leading to new prospects for nurses in the field of home health. It reflects that the changes in healthcare dynamics, though requiring quick nursing adaptations, are constantly bringing several opportunities for improving their standing in care. ${ }^{10}$

Correspondence to: Ms. Nasreen Rafiq, The Aga Khan University School of Nursing and Midwifery, Karachi, Pakistan

E-mail: nasreenrafiq93@gmail.com

Received: September 29, 2020; Revised: December 10, 2020;

Accepted: December 10, 2020

DOI: https://doi.org/10.29271/jcpsp.2020.12.1243
Likewise, telemedicine and e-health is another avenue brought to nursing practice. Both the telemedicine and e-health are promising contributors in improving the standing and delivery of nursing care to patients by offering unique educational and clinical opportunities. ${ }^{11}$ Such emerging avenues in nursing field give a platform for novice nurses to explore nurse leadership roles.

Furthermore, the year has also highlighted the crucial role of nurse leaders in bringing innovation in the field of academics and education. The traditional pedagogical teaching modalities are being transformed to modern virtual learning strategies. ${ }^{12}$ These strategies have facilitated nursing practices by providing continuous learning platforms, promoting self-learning, optimising evidence-based education, ultimately improving patient care, and contributing to the overall health of the population. ${ }^{12}$ Moreover, the development in nursing education has also changed the conventional perspectives related to nurse specialist. Today, nurse leaders are identified as distinct HCPs in multidisciplinary team with diverse contributions towards the quality and safety of patient care. ${ }^{2}$

Besides, the year 2020 also terminates the three-year campaign of Nursing Now, which highlights the fundamental role of nurse leaders in the global healthcare system. ${ }^{13}$ Hence, the campaign has introduced new prospects to nurses to opt for the leadership roles. The nurses are actively engaged in leadership roles, not only in the in-patient departments but also in the out-patient clinics, tele-medicine, community-based programmes, and policy development for improving care. ${ }^{14}$ This brings the role of nursing leadership in limelight, and generates a dire need to acknowledge this role in the global healthcare system.

The year 2020 and the coronavirus pandemic give a global reminder for the revolution in the image of nursing. With this pandemic, where people have become more fearful about their current health and immunity, the nursing leadership has ensured accomplishment of its roles and responsibilities.

In fact, nurses have become more vigilant and cautious in providing care and educating the population to promote wellbeing. It also reminds that nurses make a huge portion of the healthcare workforce, and they play a pivotal role in the healthcare system. Hence, it becomes important to invest in nursing education to improve the standing of nurses to enhance leadership role in the global healthcare system.

In conclusion, the year 2020 reflects the audacious and courageous role of nurses towards the promotion of in medicine in terms of research, education, and leadership role. Moreover, it 
can be a reflection that the year has brought various opportunities for nursing, which has improved its standing in the global healthcare system. This moment can also be used as a point of self-realisation that nursing is the backbone of healthcare. Hence, more efforts should be made to increase the viability of nurses around the world. With increasing viability, nurses should deserve an appreciation, too, for successfully adapting in their evolving role and for providing standard and quality of care to the patients.

\section{REFERENCES}

1. Aquilia A, Grimley K, Jacobs B, Kosturko M, Mansfield J, Mathers C, et al. Nursing leadership during COVID-19: Enhancing patient, family and workforce experience. Patient Experience J 2020; 7(2):136-43. Doi: 10.35680/ 2372-0247.1482.

2. Brooks E. From shadow to change agent: Revitalisation of the clinical nurse specialist role. Nursing Forum 2020; 55(2):pp.297-300). doi: 10.1111/nuf.12429.

3. Kouri $\mathrm{P}$, Ahonen $\mathrm{O}$. The role of nurses in developing of ehealth services-case Finland. J Comp Nurs Res Care 2018; 3:129. doi.org/10.33790/jcnrc1100129.

4. So W. Development and implementation of evidencebased practice in cancer care: Challenges and opportunities. APJON 2016; 3(1):33. doi: 10.4103/23475625.178168

5. Perrin M, Kim T, Stan R, Giesie P, Tabor J, Le Verche V, et al. Stem Cells Transl Med 2018; 7(1):6-10. doi: 10.1002/ sctm.17-0165.

6. Kaye RJ. Overview of stem cell therapy for acute respiratory distress syndrome with focus on COVID 19.
Pain Physician 2020; 23(4S):S425-34.

7. Sung AD, Nichols KR, Chao NJ. House calls for stem cell transplant patients during the COVID-19 pandemic. Blood 2020; 136(3):370-1. doi: 10.1182/blood.2020006573.

8. The Nurse's Role in Preparing Patients for Stem Cell Transplantation [Internet]. Aplastic Anemia \& MDS International Foundation. 2020 [cited 18 September 2020]. Available from: http://www.aamds.org/nurse $\%$ E2 \% 80\% 99s-role-preparing-patients-stem-celltransplantation.

9. Porzio G, Cortellini A, Bruera E, Verna L, Ravoni G, Peris F, et al. Home care for cancer patients during COVID-19 pandemic: The double triage protocol. J Pain Symptom Manag 2020; 60(1):e5-7. doi: 10.1016/j. jpainsymman.2020.03.021.

10. Martland AM, Huffines $M$, Kiersten Henry DN. Surge priority planning COVID-19: Critical care staffing and nursing considerations. Chest 2020.

11. Doorenbos AZ, Jang MK, Li H, Lally RM. eHealth education: Methods to enhance oncology nurse, patient, and caregiver teaching. Clin J Oncol Nurs 2020; 24(3): 42-8. doi: 10.1188/20.CJON.S1.42-48.

12. Wu XV, Chan YS, Tan KH, Wang W. A systematic review of online learning programs for nurse preceptors. Nurse Edu Today 2018; 60:11-22. doi: 10.1016/j.nedt.2017.09.010.

13. International council of nursing. Nursing now campaign.2020. Available at: www.icn.ch/ what-wedo/campaigns/nursing-now. Accessed June 24, 2020.

14. Rishel CJ. The role of resilience and mindful leadership in oncology nursing. Oncol Nurs Forum 2015; 42(2):198-9. doi: 10.1188/15.ONF.198-199. 